\title{
RELAÇÃO ENTRE ESTILOS DE APRENDIZAGEM E CARACTERÍSTICAS DOS ESTUDANTES DE CIÊNCIAS CONTÁBEIS: UMA INVESTIGAÇÃO A PARTIR DO MODELO DE FELDER \& SILVERMAN (1988)
}

\section{RELATIONSHIP BETWEEN LEARNING STYLES AND CHARACTERISTICS OF ACCOUNTING STUDENTS: AN INVESTIGATION BASED ON FELDER \& SILVERMAN MODEL (1988)}

XVIII USP International Conference in Accounting, realizado de 25/7 a 27/7 de 2018, em São Paulo (SP).

\section{RESUMO}

O presente estudo teve o objetivo de identificar os estilos de aprendizagem predominantes entre os estudantes de Ciências Contábeis e analisar sua associação com o gênero, período do curso, faixa etária e estado civil, em uma das maiores universidades privadas do país. O estudo de natureza descritiva, do tipo survey e com abordagem descritiva, utilizou dados coletados a partir do questionário elaborado por Felder e Soloman (1991), traduzido por Kuri (2004), e foi aplicado em uma amostra com 133 estudantes do curso no turno da noite. Os dados foram analisados a partir da estatística descritiva e teste de independência (Qui-quadrado). Os resultados evidenciaram que, na dimensão Percepção, o estilo Sensorial foi predominante (87,96\%); na dimensão Entrada, predominou o estilo Visual (57,14\%); na dimensão Processamento, predominou o estilo Reflexivo (55,63\%) e, na dimensão Entendimento, predominou o estilo Global $(58,64 \%)$ Verificou-se que existe uma associação estatisticamente significativa (ao nível de $5 \%$ ) dos estilos de aprendizagem com o período e a idade dos estudantes de Ciências Contábeis participantes da amostra. Esses resultados sugerem uma mudança, ao longo do tempo, na forma como os estudantes de Ciências Contábeis aprendem. Diante disso, os resultados contribuem com os professores e as instituições, no sentido de se pensar em políticas e práticas pedagógicas que considerem os respectivos estilos de aprendizagem, a idade do estudante e o período em que se encontram no curso, visando à melhoria da qualidade do processo de ensino-aprendizagem.

Palavras-Chave: Estilos de Aprendizagem. Ensino-Aprendizagem. Felder-Silverman.

\begin{abstract}
This study aimed to identify the predominant learning styles among students of Accounting Sciences and to analyze their association with gender, academic term, age group and marital status in one of the largest private universities in the country. The study was descriptive, using data collected from the questionnaire developed by Felder e Soloman (1991), translated by Kuri (2004), and applied in a sample with 133 students that take evening classes. The data were analyzed based on descriptive statistics and on the Chi-Square Test of Independence. The results evidenced that in the perception dimension, the sensorial style was predominant (87.96\%); in the input dimension, the visual style (57.14\%) was predominant; in the Processing dimension, the Reflective style (55.63\%) was predominant and in the Understanding dimension, the Global style $(58.64 \%)$ was predominant. It was verified that there is a statistically significant association (at the 5\% level) among learning styles, the academic term and the age of the Accounting students participating in the sample. These results suggest a change over time in the way Accounting students learn. Therefore, the results contribute to the development of new policies and pedagogical practices, by teachers and institutions, that consider different learning styles, the age of the student and the period in which they are in the course, aiming to improve the quality of the teaching-learning process.
\end{abstract}

Keywords: Learning Styles. Teaching-Learning. Felder-Silverman.
Roanjali Aux. Gonçalves Salviano Araújo Doutoranda e Mestre em Educação pela Pontifícia Universidade Católica de Minas Gerais (PUC Minas). specialista em Gestão Estratégica e Finanças pela Universidade Federal de Minas Gerais (UFMG). Bachare em Ciências Contábeis pela PUC Minas. Docente do Instituto de Ciências Econômicas e Gerenciais (Iceg) da PUC Minas, membro do Núcleo Docente Estruturante (NDE) do curso de Ciências Contábeis da PUC Minas Coração Eucarístico, Coordenadora de Pesquisa do curso de Ciências Contábeis da PUC Minas Barreiro e docente da PUC Minas em Contagem. Contato: Rua Rio Comprido, 4580 - Bairro Cinco - Contagem/MG - CEP 32265-450. E-mail: roanjali@pucminas.br

\section{Lilian Karolina Correia da Silva}

Bacharel em Ciências Contábeis pela Pontifícia Universidade Católica de Minas Gerais (PUC Minas). Analista Contábil em Multinacional do Grupo Vinci Energies e ex-auditora da KPMG Auditores ndependentes. Contato: Via Expressa de Contagem, 3850 - Bairro Cinco - Contagem/MG - CEP 32.370485. E-mail: liliankarolinah@hotmail.com

\section{Vagner Antônio Marques}

Doutor em Administração (Finanças) e Mestre em Ciências Contábeis pela Universidade Federal de Minas Gerais (UFMG). Especialista em Gestão de Negócios pelo Instituto Brasileiro de Mercado de Capitais (Ibmec). Bacharel em Ciências Contábeis pela Pontifícia Universidade Católica de Minas Gerais (PUC Minas). Coordenador e Docente do PPGCon - Programa de Pós-graduação em Ciências Contábeis da Universidade Federal do Espírito Santo (UFES). Contato: Av. Fernando Ferrari, 514 - Goiabeiras - Vitória/ES - CEP-29.075-910 E-mail:vagner.marques@ufes.br

\section{José Wilson da Costa}

Doutor em Ciências da Informação pela Universidade Federal de Minas Gerais (UFMG). Mestre em Engenharia Elétrica pela Universidade Federal de Minas Gerais (UFMG). Graduação em Engenharia pela Universidade Federal de Minas Gerais (UFMG). Docente do departamento de Ciências da Computação da Pontifícia Universidade Católica de Minas Gerais (PUC Minas) e do Programa de Pós-graduação em Educação da PUC Minas. Docente do ensino técnico e profissional do Centro Federal de Educação Tecnológica de Minas Gerais (CEFET/MG). Contato: Av. Itaú, 505 - Bairro Dom Cabral - Belo Horizonte/MG - CEP 30535-012. E-mail: jwcosta@gmail.com 


\section{INTRODUÇÃO}

Com o crescimento do número de cursos, maior heterogeneidade dos estudantes e a necessidade de se garantir níveis mínimos de qualidade legalmente e mercadologicamente definidos, questões têm emergido, entre elas, o processo de ensino-aprendizagem. Santos, Pires, Macambira e Bruni (2013) observam que os estudos sobre o processo de ensino-aprendizagem no curso de Ciências Contábeis têm crescido, pois a necessidade de se adequar os conteúdos, os processos e as estratégias de ensino à realidade contemporânea aumentou. Além disso, as pressões decorrentes do mercado de trabalho têm exigido reflexões e evidências sobre como características e os perfis dos estudantes afetam a eficiência e eficácia da aprendizagem dos egressos. Logo, as estratégias de ensino utilizadas, o conteúdo/conhecimento transmitido/adquirido e sua aplicação no exercício profissional têm sido uma preocupação constante (OLIVEIRA et al., 2013).

Segundo Pavione, Avelino e Francisco (2016), entre os fatores preponderantes do processo de ensino-aprendizagem, destacam-se: a didática, o conteúdo da disciplina, a motivação do aluno e o acervo da biblioteca. Como a didática tem sistematicamente sido considerada como relevante ao processo de ensino-aprendizagem (ANTONELLI; COLAUTO; CUNHA, 2012; REZENDE; LEAL, 2013; CRUZ et al., 2017), aspectos como as estratégias de ensino e a forma como os indivíduos aprendem têm tido atenção dos pesquisadores na área de ensino e pesquisa em contabilidade. Santos, Pires, Macambira e Bruni (2013) observam que 41,2\% dos estudos publicados sobre Ensino e Aprendizagem nos Congressos USP de Contabilidade e na Associação Nacional de Programas de Pós-Graduação em Ciências Contábeis (Anpcont), no período de 2007-2011, referiram-se a temas relacionados aos aspectos comportamentais discentes e docentes, o que engloba temas relacionados às práticas docentes e aos estilos de aprendizagem.

Nesse contexto, uma questão inequívoca e que merece atenção refere-se aos estilos de aprendizagem. Schimdt e Domingues (2016) observam que existe uma diversidade de definições sobre o que vêm a ser estilos de aprendizagem, porém, pode-se sintetizar tal conceito como o conjunto de características cognitivas, psicológicas e comportamentais que afetam a forma como os indivíduos aprendem um determinado conteúdo, por conseguinte, a eficácia das estratégias de ensino utilizadas pelos docentes. Esses autores analisaram as propostas de modelos para identificação dos estilos de aprendizagem que têm sido desenvolvidas, destacando-se: (1) Dunn e Dunn (1978), (2) Grecorc (1979), (3) Kolb (1984), (4) Felder e Silverman (1988) e (5) Fleming (2001).

Miranda e Morares (2008) argumentam que muitos especialistas em relação à temática estilos de aprendizagem têm sinalizado uma preferência pelo Learning Styles Questionares, de Honey-Alonso (1992-1999), em estudos europeus. Na área de Ciências Contábeis, o Inventário de Kolb, denominação atribuída à terminologia proposta por Kolb (1984), tem sido recorrentemente utilizado em pesquisas sobre estilos de aprendizagem no contexto brasileiro (CONCEIÇÃO et al., 2013; SANTOS et al., 2014; SANTOS et al., 2013; TURRA; JACOMOSSI; BIAVATT, 2015).

Em síntese, essas ferramentas possibilitam que se identifique a forma como os indivíduos aprendem. Considerando a diversidade de ferramentas e estratégias didáticas e que cada uma delas pode apresentar maior ou menor eficiência e eficácia no processo de ensino-aprendizagem, a observação de um padrão de perfil dos estudantes aumenta a probabilidade de obtenção de sucesso, tanto na perspectiva docente, quanto discente (PAVIONE; AVELINO; FRANCISCO, 2016).

Por outro lado, a predominância de estudos que utilizaram o Modelo de Kolb (1984), bem como a necessidade de replicação e ampliação da amostra de participantes dos estudos anteriores, faz com que se observe uma lacuna na literatura sobre o tema, pois a proposta de Felder e Silverman (1988) pode contribuir para se aprofundar o conhecimento sobre o tema (KURI, 2004).

Diante desse contexto, o presente estudo buscou responder à seguinte pergunta: Qual a relação entre estilos de aprendizagem dos estudantes de Ciências Contábeis e suas características? O objetivo geral do estudo foi identificar os estilos de aprendizagem predominantes entre os estudantes de Ciências Contábeis de uma universidade privada de Minas Gerais, conforme o Modelo de Felder-Silverman (1988). Para tanto, realizou-se o estudo de natureza descritiva, do tipo survey e com abordagem quantitativa, analisando-se dados de 133 alunos dos $2^{\circ}, 4^{\circ}, 6^{\circ}$ e $8^{\circ}$ períodos do curso de Ciências Contábeis. A análise foi realizada a partir da estatística descritiva e do teste de independência (Qui-quadrado). O instrumento de coleta utilizado foi o proposto Felder-Solomon (1991), traduzido por Kuri (2004) e considerado um instrumento confiável para identificação do estilo de aprendizagem (SILVA; OLIVEIRA NETO, 2010).

A identificação dos estilos de aprendizagem e sua relação com características dos estudantes contribuem para o desenvolvimento do conhecimento sobre a temática, sobretudo em decorrência de uma predominância de estudos que utilizaram o Modelo de Kolb (1984). Isso significa que compreender os perfis observados a partir de outros modelos, nesse caso, o de Felder-Silverman (1988), possibilitará identificar convergências e divergências com relação aos resultados de estudos anteriores. Além disso, a consolidação do conhecimento sobre o tema pode direcionar as estratégias e práticas docentes de acordo com os perfis predominantemente identificados, bem como possibilitar que os agentes envolvidos, instituição-aluno-professor, repensem seus papéis e comportamentos com vistas a atingir os objetivos de todo processo de ensino-aprendizagem. Especificamente, a compreensão do estilo de aprendizagem dos estudantes pode direcionar professores quanto à forma como conduzem seus processos de ensino e de aprendizagem, respectivamente.

O trabalho está dividido em cinco seções, além desta introdução. Na segunda seção, discute-se sobre as abordagens didáticas e seus reflexos, sobre os principais modelos de estilos de aprendizagem e apresentam-se resultados de pesquisas anteriores na área de contabilidade. Na terceira seção, apresentam-se os procedimentos metodológicos uti- 
lizados no estudo. Posteriormente, realiza-se a análise dos dados, confrontando-os com os estudos anteriores. Por fim, apresentam-se as considerações finais e sugestões para pesquisas futuras.

\section{REVISÃO DA LITERATURA}

\subsection{Categorias de modelos de estilos de aprendizagem}

Os estilos de aprendizagem referem-se à forma como os indivíduos recebem, processam e assimilam o conhecimento. Chen, Jones e Moreland (2014) destacam que a desconsideração da maneira como os indivíduos preferem aprender pode implicar em ineficiência no processo de ensino-aprendizagem, pois, em muitos casos, isso reflete na dificuldade do aluno e, em último caso, no abandono da escola.

De acordo com Fatt (1995), a preocupação com os estilos de aprendizagem pode ser observada na literatura de 1892, mas foi provavelmente Thelen, em 1954, que utilizou o termo pela primeira vez. Complementam os autores que a discussão evoluiu a partir da Teoria de Kolb. Para ele, a aprendizagem é um processo circular, em que a experiência concreta, a reflexão, observação, conceitos abstratos, generalizações e experimentações ativas interagem continuamente (HONEY; MUMFORD, 1986 apud FATT, 1995).

Para Duff (2004), a Teoria Kolbiana, denominada como "Inventário de Estilos de Aprendizagem de Kolb”, considera que existem quatro estilos distintos e que os indivíduos transitarão por eles em um processo dialético. Esses quatro estágios, (1) experiência concreta, (2) observação e reflexão, (3) formação e generalização de conceitos abstratos e (4) testes de conceitos e aplicações em novas realidades (experiência concreta), sinalizam às partes envolvidas (aluno e professor) as principais maneiras com as quais um indivíduo aprende de forma mais eficiente.

Baldwin e Reckers (1984) reforçam que o Inventário de Estilos de Aprendizagem de Kolb tem influenciado as pesquisas sobre a temática. Entretanto, Ospina, Salazar e Meneses (2013) demonstram que diversos foram os modelos de estilos de aprendizagem propostos nas últimas décadas. Esses autores, após uma revisão da literatura, verificaram que, de 1920 a 2010, pelo menos oito categorias de modelos de estilos de aprendizagem foram encontradas, conforme a Figura 1.

Figura 1 - Modelos de Estilos de Aprendizagem

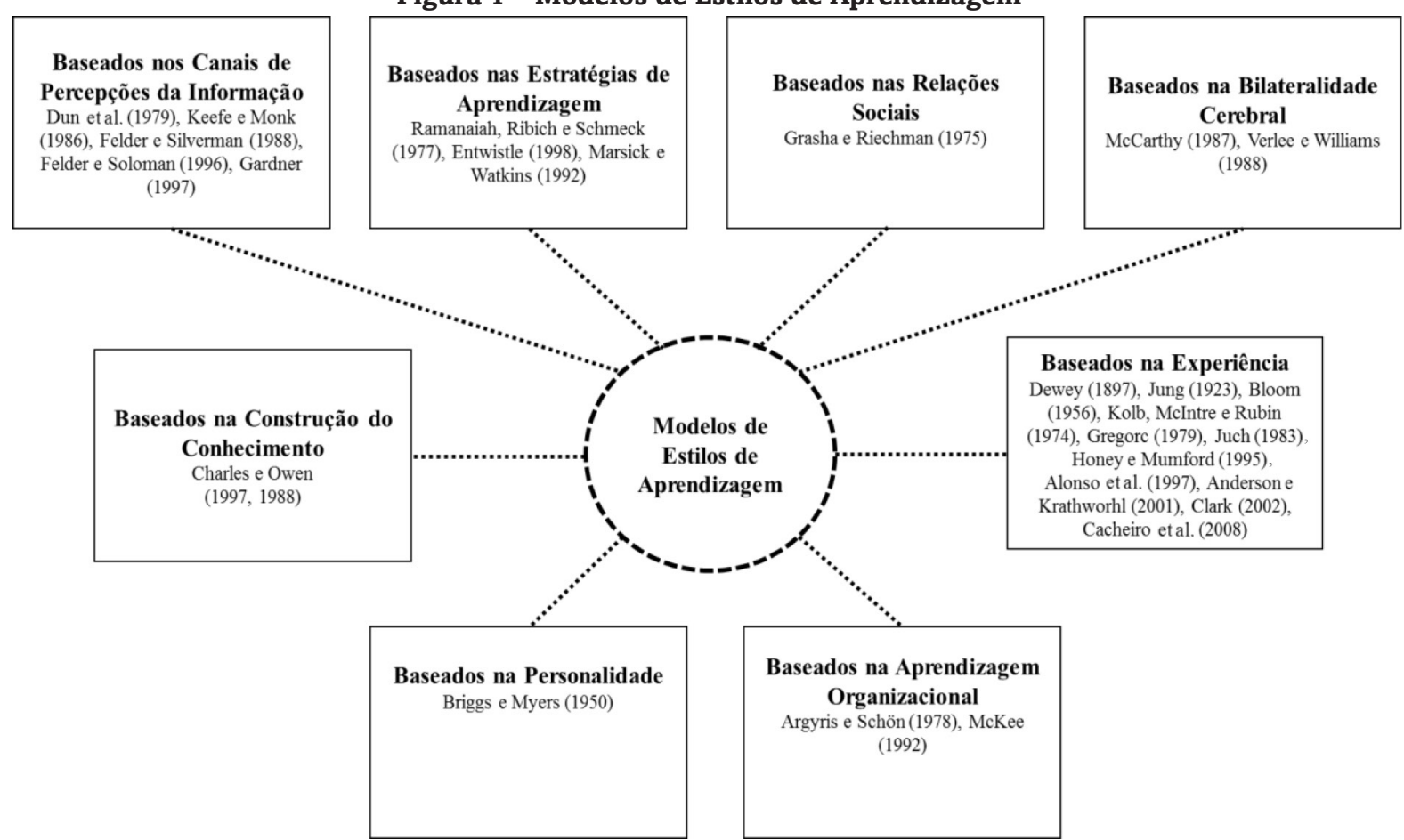

Fonte: Adaptado de Ospina, Salazar e Meneses (2003).

No primeiro grupo, aqueles baseados nos Canais de Percepção da Informação, estão classificados os modelos em que os aspectos cognitivos e sensoriais são componentes relevantes para o processo de ensino e aprendizagem, isso significa dizer que o "canal", a forma como o conhecimento será disseminado, pode afetar positiva ou negativamente o processo. Nesses modelos, Felder e Silverman (1988), por exemplo, defendem que cada indivíduo possui diversas dimensões de relacionamento com o objeto de aprendizagem e cada um terá suas preferências, variando entre: (i) a forma como processam a informação (ativo/reflexivo), (ii) a preferência pelo tipo de informação (sensitivo/intuitivo), 
(iii) a forma mais eficaz de receber a informação (visual/verbal) e (iv) o processo evolutivo (sequencial/global). Segundo Ospina, Salazar e Meneses (2013), além de Felder e Silverman (1988), destacam-se nessa categoria Dunn et al. (1979), Gardner (1997), entre outros.

De acordo com Ospina, Salazar e Meneses (2013), nos modelos baseados na Estratégia de Aprendizagem, o método com o qual o educando recebe, processa e assimila o conteúdo define o estilo de aprendizagem. Nesses modelos, os estilos de aprendizagem são classificados em profundo, de elaboração e superficial (RAMANAIAH; RIBICH; SCHMECK, 1977).

Marsik e Watkins (1992) classificam os estilos em formal, informal e incidental. Por fim, de acordo com Entwistle (1998), os estilos de aprendizagem se classificam em superficial, profundo e estratégico. Nesses modelos, um ambiente adequado propicia uma maior eficiência, pois estimula o estudante a aprender, uma vez que considera sua individualidade. Isso implica dizer que a adoção de práticas didáticas propícias ao estilo superficial pode desestimular aqueles indivíduos cujo estilo estratégico seja predominante, do mesmo modo que ambientes de aprendizagens formais podem desestimular aqueles com estilo informal.

Entre os modelos baseados nas Relações Sociais, a aprendizagem colaborativa e interacionista ganha maior relevância. Grasha e Riechman (1975) classificam os estilos de aprendizagem quanto às atitudes do aluno (participativo/ elusivo), quanto à relação com os colegas (competitivo/colaborativo) e quanto aos procedimentos didáticos (dependente/independente). Observa-se que, nesses modelos, o desenvolvimento de atividades em grupos que colocam indivíduos com características que estimulam a cooperação entre os participantes é essencial para o atendimento ao objetivo do processo de ensino-aprendizagem (OSPINA, SALAZAR; MENESES, 2013).

Ospina, Salazar e Meneses (2013) afirmam que McCarthy (1987) e Verlee Willians (1988) propuseram um modelo com base na Bilateralidade Cerebral para classificar os estilos de aprendizagem. Partindo das categorias estabelecidas por Kolb (1984), os autores classificam os estilos de aprendizagem conforme a região cerebral mais estimulada (direito/ esquerdo). De acordo com essa perspectiva, esses estilos são categorizados em sinistro hemisférico e destro hemisférico. Na prática, tal classificação evidencia as habilidades cognitivas predominante dos indivíduos.

Segundo Luz, Gama e Santos (2004), apesar de o cérebro trabalhar em harmonia, alguns indivíduos desenvolvem assimetricamente um lado em relação ao outro, implicando que:

O lado esquerdo do cérebro que é responsável pelas atividades lógicas, verbais, racionais, dentre outras. O lado direito, por sua vez, é a parte do cérebro que permite o raciocínio holístico, espontâneo, intuitivo e criativo, relacionado com a análise emocional, subjetiva, mística e romântica, diferindo-se do modelo de raciocínio fragmentado, típico da lógica cartesiana. A diferença entre eles é grande: pessoas com o lado esquerdo dominante resolvem problemas com base em fatos, analiticamente, privilegiando palavras, números e ocorrências apresentadas em seqüência lógica; pessoas com o lado direito dominante procuram por imagens, conceitos, padrões, sons e movimentos, que levam a uma solução intuitiva. (LUZ; GAMA; SANTOS, 2004, p. 2)

Nos modelos baseados na Experiência, David Kolb é o teórico com maior destaque. Não por sua proposta ser melhor que as demais, mas porque propôs um modelo analítico que classifica os indivíduos em categorias que se conectam à realidade da maioria dos contextos educacionais. Segundo Kolb (1984), quatro perfis diferenciam os indivíduos em termos de estilo de aprendizagem: (1) Divergente, (2) Assimilador, (3) Convergente e (4) Acomodado.

De acordo com Chen, Jones e Moreland (2014), a aprendizagem a partir da experiência se inicia com um processo sensorial e segue por uma fase de observações e reflexões. Após essa etapa, o indivíduo adquire uma capacidade de abstração, finalizando com a experimentação ativa: quando o sujeito de aprendizagem tem condições de aplicar o aprendido. Os modelos de experiência consideraram que o empirismo está na base do processo de ensino aprendizagem, o que é coerente com abordagens pedagógicas não tradicionais. Apesar de Kolb ser a referência nesses modelos, Ospina, Salazar e Meneses (2013) observam que, nessa categoria, destacam-se ainda: Dewey (1897), Jung (1923), Bloom (1956), Kolb, McIntre e Rubin (1974), Gregorc (1979), Juch (1983), Honey e Mumford (1995), Alonso et al. (1997), Anderson e Krathworhl (2001), Clark (2002), Cacheiro et al. (2008).

Os modelos baseados na Aprendizagem Organizacional buscam, em essência, identificar como indivíduos aprendem no ambiente de trabalho. De acordo com Mckee (1992 apud OSPINA; SALAZAR; MENESES, 2013), os colaboradores podem ser classificados em quatro estilos: (i) interpessoal, (ii) analítico, (iii) organizacional e (iv) ecológico. Segundo o autor, a compreensão desses estilos no ambiente empresarial pode contribuir para que se desenvolva um processo de inovação contínuo.

Briggs e Myers (1950 apud OSPINA; SALAZAR; MENESES, 2013) desenvolveram uma proposta em que a Personalidade é o parâmetro para a classificação dos estilos, a qual considera a forma como o indivíduo recebe e reage ao conteúdo ensinado. Seus precursores afirmam que os indivíduos irão receber e reagir ao ensinado em função da motivação, do modo como percebem a informação, do modo como a utilizarão e da forma como enxergam o mundo.

Por fim, nos modelos baseados na Construção do Conhecimento, a classificação dos estilos de aprendizagem ocorre a partir da identificação de como as pessoas abstraem, dividindo-se normalmente em duas fases: uma primeira, analítica e detalhada, e outra, que busca a síntese, experimentação e criação. Desse modo, nesse modelo, os indivíduos classificarão o conhecimento em teórico e prático (OSPINA; SALAZAR; MENESES, 2013). 


\subsection{Estilos de aprendizagem de acordo com o modelo de Felder e Silverman (1988)}

A aprendizagem para Felder e Silverman (1988) refere-se à preferência do sujeito em receber e processar o conhecimento, ou seja, é uma classificação que envolve os tipos de estilos de aprendizagem e suas dimensões. As informações são aprendidas na etapa de recepção do conhecimento, na qual são recebidas pelos sentidos e informações internas, sendo selecionadas pelo sujeito de aprendizagem por ordem de importância e descartadas as informações que considerar desnecessárias. Após "peneirar" as informações que ficarão registradas, inicia-se a etapa de processamento. Pela lógica dos autores, o conteúdo é aprendido de uma das duas formas ou, ainda, o conteúdo pode não ser retido, não gerando efetivamente o aprendizado (SILVA; LEAL; PEREIRA; OLIVEIRA NETO, 2016).

Assim como Honey e Munford (1986), Felder e Silverman (1988) também utilizaram como base para sua teoria os trabalhos desenvolvidos por Kolb (1984), adicionando a esse as características da teoria dos tipos psicológicos, segundo o Myers-Briggs Type Indicator (MBTI). Felder e Silverman (1988) dividiram os estilos de aprendizagem em quatro dimensões, a saber: (1) Percepção (Sensorial ou Intuitiva), (2) Entrada (Visual ou Verbal), (3) Processamento (Ativo ou Reflexivo) e (4) Entendimento (Sequencial ou Global).

Segundo Vieira Junior e Colvara (2006), a dimensão Percepção está relacionada às maneiras como os fatos ocorridos em torno do indivíduo são percebidos. Sensoriais saem-se melhor ao analisar fatos e dados, utilizam métodos práticos, são detalhistas, mas não possuem facilidade com símbolos, geralmente evitam complicações e utilizam dos sentidos para coletar informações. Os intuitivos utilizam preferencialmente a especulação e intuição, costumam ser mais rápidos que os sensoriais, mas estão mais propensos a erros, possuem grande facilidade com símbolos e teorias, além de procurar resolver os problemas de forma inovadora.

No que tange à dimensão Entrada, observa-se a facilidade de memorização de formas ilustrativas ou verbais. Dessa forma, o visual é aquele estudante que, através de esquemas, diagramas, demonstrações e figuras, tende a fixar melhor o conteúdo. Em contrapartida, o verbal lida melhor com informações escritas, faladas e ouvidas (LINDEMANN, 2008).

O processo mental de conversão das informações captadas em conhecimento concreto é caracterizado na dimensão Processamento. Dias, Sauaia e Yoshizaki (2013) afirmam que essa dimensão tem forte relação com a experimentação ativa e observação reflexiva, proposta por David Kolb (1984). Os autores explicam que os sujeitos ativos, conforme se percebe na nomenclatura, tendem a aprender participando de atividades em grupo, experimentando e aplicando conceitos. São eficientes ainda em fixar o conteúdo explicando para os demais. Os reflexivos são característicos por refletirem sobre os fatos, não são agentes passivos, mas necessitam pensar sobre o assunto, por isso, estão propensos a serem teóricos. Além disso, trabalham melhor sozinhos ou em dupla.

A organização da informação para a aplicação em novos fatos é o "ponto-chave" da dimensão Entendimento, uma vez que reflete o tratamento por etapas sequenciais ou por uma visão global do assunto.

Dessa forma, para os sequenciais, o aprendizado torna-se efetivo e eficiente quando o tema é apresentado por uma cadeia que expressa o passo a passo de forma linear, aguçando a capacidade de análise, enquanto os globais preferem abordar o assunto de forma completa. Assim, tendem a ter dificuldades com material de entendimento parcial e com os métodos das escolas tradicionais. Possuem, ainda, habilidade de resolver problemas de forma ágil (SILVA et al., 2016).

Para identificar os Estilos de Aprendizagem dos indivíduos, Felder e Soloman (1991) utilizaram-se também, como a maioria dos autores, de um questionário, o Index of Learning Styles (ILS), que contém quarenta e quatro questões com duas opções cada uma, resultando num total de onze questões para cada dimensão.

Dependendo da pontuação obtida, o entrevistado é classificado em três escalas de preferência: forte (9-11), moderada (5-7) e fraca (1-3), conforme pode ser observado na Figura 2: 
Figura 2 - Escala dos Estilos de Aprendizagem de acordo com o modelo Felder e Silverman (1988)

Dimensões

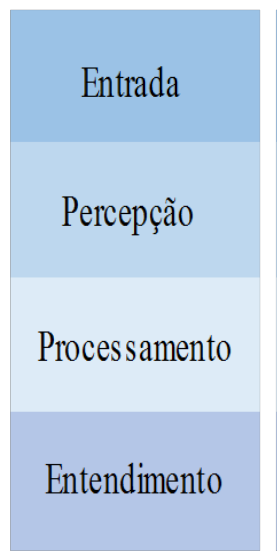

Estilos

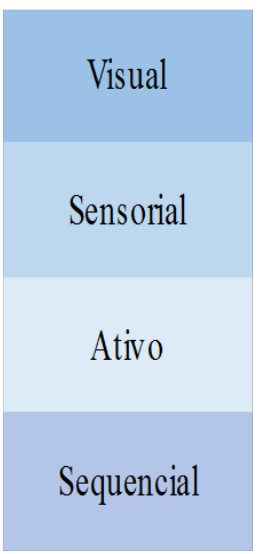

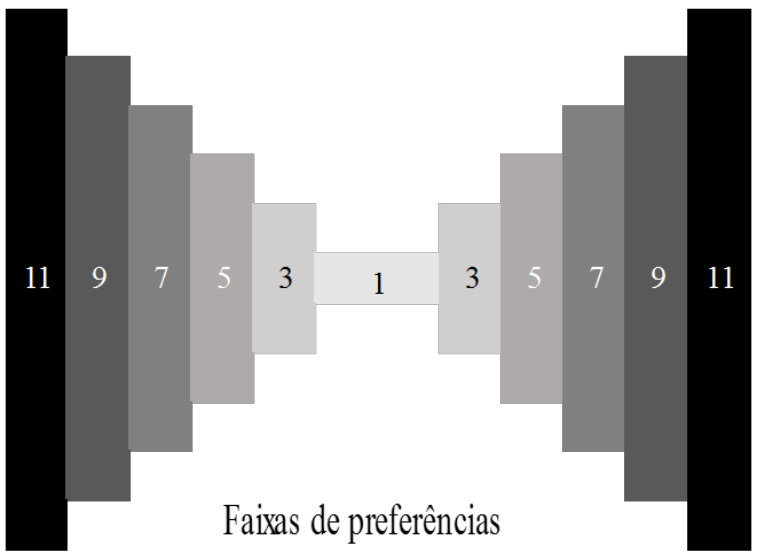

Estilos

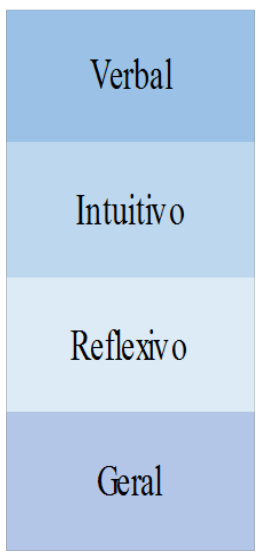

Fonte: Adaptado a partir de Felder e Soloman (1991).

Nota: Nas faixas de 1-3, a intensidade é fraca; entre 5-7, moderada e, entre 9-11, forte.

Dias, Sauaia e Yoshizaki (2013) explicam que o resultado obtido com o ILS, entre um e três, aponta que o aprendiz não tem preferência por determinado estilo de aprendizagem. Entre cinco e sete, há uma preferência moderada, em que o aprendizado se torna mais eficiente quando o ambiente escolar considera os estilos preferenciais dos alunos. Quando o resultado está entre nove e onze, o aluno apresenta forte preferência por determinado estilo de aprendizagem: isso significa que, em um ambiente de ensino que não considera os EA dos aprendizes, aquele que tem forte preferência tende a ser prejudicado e apresentar dificuldades.

\subsection{Pesquisas Anteriores}

Os estilos de aprendizagem têm sido estudados em diversas áreas (CAMERON et al., 2015), em grande medida por influência da evolução das abordagens pedagógicas (MUZIAMI, 1986; LIBÂNEO, 2005), do desenvolvimento tecnológico (HOLTZBLATT; TSCHAKERT, 2011) e das relações e interações sujeito-objeto (RAMSAY; HANLON; SMITH, 2000).

Apostolou, Dorminey, Hassel e Rebele (2015) afirmam que os estudos sobre estilos de aprendizagem no âmbito da contabilidade têm sido realizados em diversos contextos e perspectivas, tais como na avaliação de eficiência, associação com o currículo, desempenho do estudante, etc.

No contexto brasileiro, os estudos sobre estilos de aprendizagem são pesquisados, principalmente, a partir do Inventário de Kolb (SILVA; OLIVEIRA NETO, 2010; SANTOS et al., 2013; OLIVEIRA et al., 2013; CONCEIÇÃO et al., 2013; TURRA; JACOMOSSI; BIAVATT, 2015; LIMA FILHO; BEZERRA; JESUS SILVA, 2016).

Entretanto, Silva e Oliveira Neto (2010), Schmidt e Domingues (2016), Souza, Avelino e Takamatsu (2017) analisaram a questão a partir do modelo de Felder-Silverman (1988), muito utilizado em outras áreas, como a administração, pedagogia, etc.

Silva e Oliveira Neto (2010), buscando compreender os estilos de aprendizagem de alunos e professores, bem como a associação entre os estilos de aprendizagem sobre o desempenho dos estudantes, identificaram diferenças nos estilos predominantes entre alunos e professores, o que era esperado, dado o nível de desenvolvimento cognitivo de cada um. Além disso, verificaram que existe uma associação entre os estilos de aprendizagem e o desempenho dos estudantes.

Enquanto o estilo Sensorial (78,87\%) e o Visual $(71,13 \%)$ foram os predominantes entre os estudantes, o Visual $(72,41 \%)$ e o Reflexivo $(65,52 \%)$ foram os que se destacaram entre os professores. De acordo com os autores, essas características atribuem aos alunos características de análise sistemática e utilização de gráficos, ilustrações, etc., também encontrada em cursos da área de exatas.

Souza, Avelino e Takamatsu (2017) analisaram os estilos de aprendizagem de uma amostra de 84 estudantes de Ciências Contábeis em uma instituição de ensino superior federal e observaram que a maioria dos participantes apresentou, predominantemente, no nível leve, os estilos: ativo, visual, sensorial e sequencial. As autoras argumentam que essas evidências sugerem a necessidade de o processo de ensino-aprendizagem em contabilidade considerar a forma como os estudantes capturam e processam os dados, de modo a transformá-los em informação e conhecimento, pois ela se diferencia de um estudante para o outro. Logo, conhecer esse perfil contribui para se entender qual a melhor prática didática que auxiliará os estudantes a compreenderem efetivamente o conteúdo ensinado, melhorando, assim, a qualidade do ensino.

Sobre essa questão, Silva, Leal, Pereira e Oliveira Neto (2015) aplicaram o ILS de Felder-Soloman (1991) e verificaram que os estilos ativo, sensorial, verbal e sequencial se destacaram entre os estudantes participantes do estudo. A pesquisa analisou dados de 412 questionários aplicados em estudantes de cursos de especialização a distância (EaD) e 
observou que apenas o estilo reflexivo, da dimensão Processamento, apresentou correlação positiva e significativa com o desempenho, porém, nas demais dimensões, não foram observados efeitos significativos.

Borges et al. (2017) buscaram analisar se existe associação entre os estilos de aprendizagem e o desempenho dos estudantes. Para tanto, aplicaram o questionário proposto por Felder e Soloman (1991) em uma amostra de 111 alunos do $5^{\circ}$ período do curso de Ciências Contábeis. Os resultados evidenciaram que, na dimensão Processamento, a maioria dos estudantes possuía um estilo Ativo (64\%), Sensorial (80,2\%), Visual (86,5\%) e Sequencial $(65,8 \%)$. Entre as implicações, os autores afirmam que esse perfil (Ativo), na dimensão Processamento, demonstra uma preferência por abordagens didáticas dinâmicas e realizadas em grupo.

Na dimensão Percepção, o estilo sensorial é coerente com a utilização de abordagens didáticas que agucem os sentidos (visual, auditivo, sensações físicas). Na dimensão Retenção, o estilo visual sugere a preferência pela utilização de imagens entre as estratégias didáticas aplicadas. Por fim, para essa amostra, o desenvolvimento do conteúdo de forma fragmentada e sequenciada é o que se destaca na dimensão Compreensão. Os autores observaram, ainda, que não existem diferenças significativas no desempenho dos estudantes com perfis diferenciados, entretanto, destacam características do processo avaliativo da instituição e características da amostra.

\section{PROCEDIMENTOS METODOLÓGICOS}

O presente estudo classificou-se como descritivo quanto aos objetivos, do tipo survey quanto aos procedimentos e com a abordagem quantitativa quanto ao problema. A amostra do estudo foi composta por 133 estudantes de Ciências Contábeis de uma universidade privada do estado de Minas Gerais. Essa amostra corresponde a, aproximadamente, $42 \%$ do total de alunos matriculados na unidade estudada e foi distribuída entre os $2^{\circ}, 4^{\circ}, 6^{\circ}$ e $8^{\circ}$ períodos. A escolha dessa amostra intencional decorreu do interesse em avaliar se existia associação entre o estilo de aprendizagem e o período em que o aluno se encontra no curso.

Para identificar os estilos de aprendizagem dos indivíduos, foi utilizado o Index of Learning Styles Questionnaire (ILS) de Felder e Soloman (1991), traduzido por Kuri (2004), que contém quarenta e quatro questões com duas opções cada uma, resultando em um total de onze questões para cada dimensão. O questionário foi aplicado no segundo semestre de 2016.

A análise da associação entre os estilos de aprendizagem e as características, como período, idade, gênero e estado civil, decorre da literatura da área de educação, principalmente para sinalizar que os estilos de aprendizagem se alteram ao longo dos anos e fatores como as experiências vividas, o estado de bem-estar e o gênero interferem no processo. Isso porque tais características se alinham com o hábito de leitura, desenvolvimento cognitivo, maturidade, comprometimento do estudante, entre outros (WALLON, 1995; RAMSAY; HANLON; SMITH, 2000; KURI, 2004; DUFF, 2004; LINDEMAN, 2008; OSPINA; SALAZAR; MENESES, 2013; SCHMIDT; DOMINGUES, 2016).

Para testar a associação entre os estilos de aprendizagem e as características dos grupos, utilizou-se o Teste de Independência do Qui-quadrado $\left(x^{2}\right)$. O teste consiste em avaliar a hipótese nula (de que os estilos de aprendizagem são independentes das características dos estudantes (período, gênero, idade e estado civil)). Por sua vez, a hipótese alternativa (foi a de que os estilos de aprendizagem são dependentes das características dos estudantes (período, gênero, idade e estado civil). Os dados foram analisados através do SPSS 21.

\section{ANÁLISE DE DADOS E RESULTADOS}

Inicialmente, analisou-se o perfil dos estudantes participantes do estudo, conforme Tabela 1. Observou-se que 56\% da amostra referiram-se a estudantes matriculados na primeira metade do curso e o restante (44\%), no final do curso.

Tabela 1 - Caracteristica dos participantes da pesquisa

\begin{tabular}{|c|c|c|c|c|c|c|c|c|c|c|}
\hline \multirow{2}{*}{ Périodo } & \multirow{2}{*}{$\mathbf{n}$} & \multirow{2}{*}{$\%$} & \multicolumn{8}{|c|}{ Idade } \\
\hline & & & $<20$ & $\%$ & $20-25$ & $\%$ & $26-30$ & $\%$ & $>30$ & $\%$ \\
\hline $2^{\circ}$. & 49 & $37 \%$ & 30 & $61 \%$ & 13 & $27 \%$ & 6 & $12 \%$ & 0 & $0 \%$ \\
\hline $4^{\circ}$. & 26 & $20 \%$ & 6 & $23 \%$ & 12 & $46 \%$ & 3 & $12 \%$ & 5 & $19 \%$ \\
\hline $6^{\circ}$. & 22 & $17 \%$ & 0 & $0 \%$ & 16 & $73 \%$ & 5 & $23 \%$ & 1 & $5 \%$ \\
\hline $8^{\circ}$. & 36 & $27 \%$ & 0 & $0 \%$ & 30 & $83 \%$ & 6 & $17 \%$ & 0 & $0 \%$ \\
\hline Total & 133 & $100 \%$ & 36 & $27 \%$ & 71 & $53 \%$ & 20 & $15 \%$ & 6 & $5 \%$ \\
\hline
\end{tabular}




\begin{tabular}{|c|c|c|c|c|c|c|c|c|c|c|c|c|}
\hline \multirow{2}{*}{ Périodo } & \multirow{2}{*}{$\mathbf{n}$} & \multirow{2}{*}{$\%$} & \multicolumn{4}{|c|}{ Gênero } & \multicolumn{6}{|c|}{ Estado Civil } \\
\hline & & & $\mathbf{F}$ & $\%$ & $\mathbf{M}$ & $\%$ & S & $\%$ & C & $\%$ & 0 & $\%$ \\
\hline $2^{\circ}$. & 49 & $37 \%$ & 42 & $86 \%$ & 7 & $14 \%$ & 44 & $90 \%$ & 0 & $0 \%$ & 5 & $10 \%$ \\
\hline $4^{\circ}$. & 26 & $20 \%$ & 15 & $58 \%$ & 11 & $42 \%$ & 26 & $100 \%$ & 0 & $0 \%$ & 0 & $0 \%$ \\
\hline $6^{\circ}$ & 22 & $17 \%$ & 19 & $86 \%$ & 3 & $14 \%$ & 18 & $82 \%$ & 2 & $9 \%$ & 2 & $9 \%$ \\
\hline $8^{\circ}$ & 36 & $27 \%$ & 31 & $86 \%$ & 5 & $14 \%$ & 32 & $89 \%$ & 3 & $8 \%$ & 1 & $3 \%$ \\
\hline Total & 133 & $100 \%$ & 107 & $80 \%$ & 26 & $20 \%$ & 120 & $90 \%$ & 5 & $4 \%$ & 8 & $6 \%$ \\
\hline
\end{tabular}

Fonte: Dados da pesquisa.

Nota: F - Feminino. M- Masculino. S - Solteiro. C - Casado. O - Outros.

Em termos de faixa etária, verificou-se que a maioria dos estudantes (80\%) possui 25 anos ou menos, demonstrando um perfil jovem. Quanto ao gênero, corroborando as evidências de outros estudos (ANTONELLI; COLAUTO; CUNHA, 2012; CONCEIÇÃO et al., 2013; GUERRA; TEIXEIRA, 2016), 80\% dos estudantes que participaram da amostra eram do gênero feminino, sendo que $90 \%$ se declararam solteiros. Esses resultados reforçam as características dos estudantes de Ciências Contábeis observadas em outros estudos, demonstrando um perfil predominantemente de mulheres, solteiras e com idade menor ou igual a 25 anos.

\subsection{Associação entre estilos de aprendizagem e características dos estudantes}

Posteriormente, verificaram-se os tipos de estilos de aprendizagem observados na amostra nas quatro dimensões e suas intensidades, conforme o Gráfico 1.

\section{Gráfico 1 - Distribuição dos Estilos de Aprendizagem por Dimensão/Intensidade}



Fonte: Dados da pesquisa.

Verificou-se que a maioria dos estudantes apresentou estilos Reflexivo (Processamento), Sensorial (Percepção), Visual (Entrada) e Global (Entendimento). Em termos de intensidade, observou-se um equilíbrio, exceto nas dimensões Percepção e na Entrada.

No estudo realizado por Souza, Avelino e Takamatsu (2017), os estilos Ativo, Sensorial, Verbal e Sequencial foram os predominantes, o que evidencia uma divergência entre os resultados. Uma das explicações para a diferença encontrada refere-se ao perfil dos alunos. Nos estudos de Souza, Avelino e Takamatsu (2017) e Borges, Leal, Silva e Pereira (2017), os alunos eram de instituições públicas federais, enquanto, no presente estudo, os alunos eram de uma instituição privada. Apesar de os processos seletivos das instituições privadas serem mais inclusivos, as características da amostra utilizada se diferenciam daquelas de estudantes de instituições públicas, logo, a diferença encontrada se justifica.

Esse resultado demonstra que, em geral, as estratégias didáticas que incentivam os estudantes a pensar, questionar, que estimulam os sentidos e utilizam canais de transmissão visuais, com abordagens dedutivas, terão maior chance de sucesso. Além disso, sugere que não se trata simplesmente de abandonar os métodos de ensino tradicionais, pois a predominância da reflexão e da entrada via visualização sinaliza que o estudante de Ciências Contábeis precisa ser estimulado a pensar e refletir e que a visão ainda é o principal canal de entrada. 
Marques et al. (2017), analisando a percepção dos estudantes quanto às estratégias didáticas utilizadas pelos professores na perspectiva dos estudantes, observaram que, apesar de muitos professores utilizarem métodos tradicionais de ensino, os alunos ainda percebem esses métodos como relevantes para sua formação. Os autores argumentam que esses resultados podem se relacionar com a cultura didática vigente e que ainda não abandonou o tradicional, mas vem se adaptando às novas tecnologias e gerações que estão ingressando nos ambientes de ensino.

Analisando os estilos de aprendizagem por período, conforme o Gráfico 2, verifica-se que a dimensão Percepção foi a única em que, graficamente, pode-se observar uma independência entre o estilo de aprendizagem (sensorial/intuitivo) e os períodos em que o estudante se encontra, pois a distribuição dos estilos foi relativamente homogênea.

\section{Gráfico 2 - Distribuição de Frequência dos Estilos de Aprendizagem por Dimensão/Períodos} 2.1 - Dimensão Percepção(Sensorial/Intuitivo)

2.2 - Dimensão Entrada (Verbal/Visual)
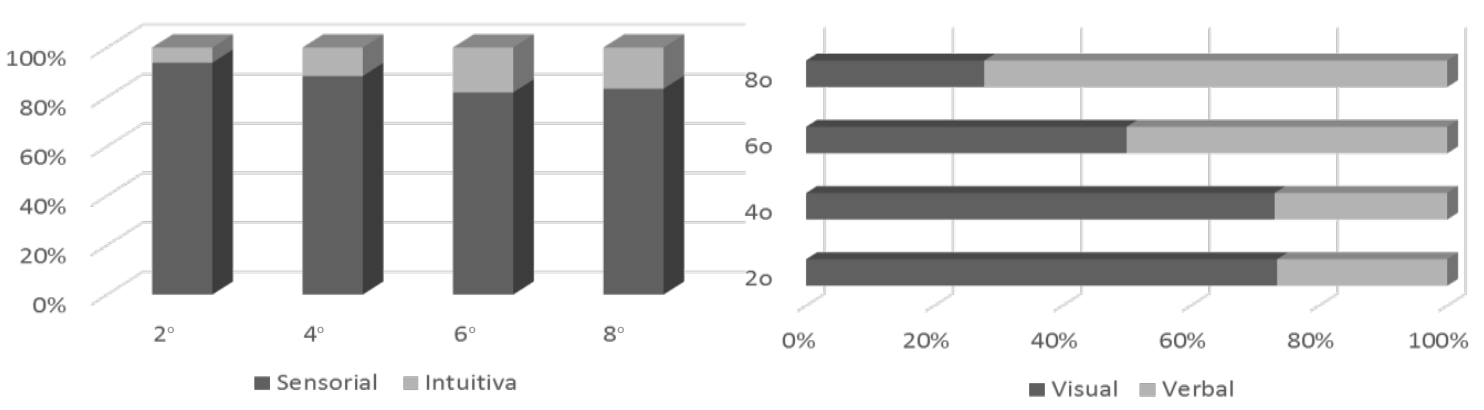

2.3 - Dimensão Processamento (Ativo/Reflexivo)

2.4 - Dimensão Entendimento (Global/Sequência)
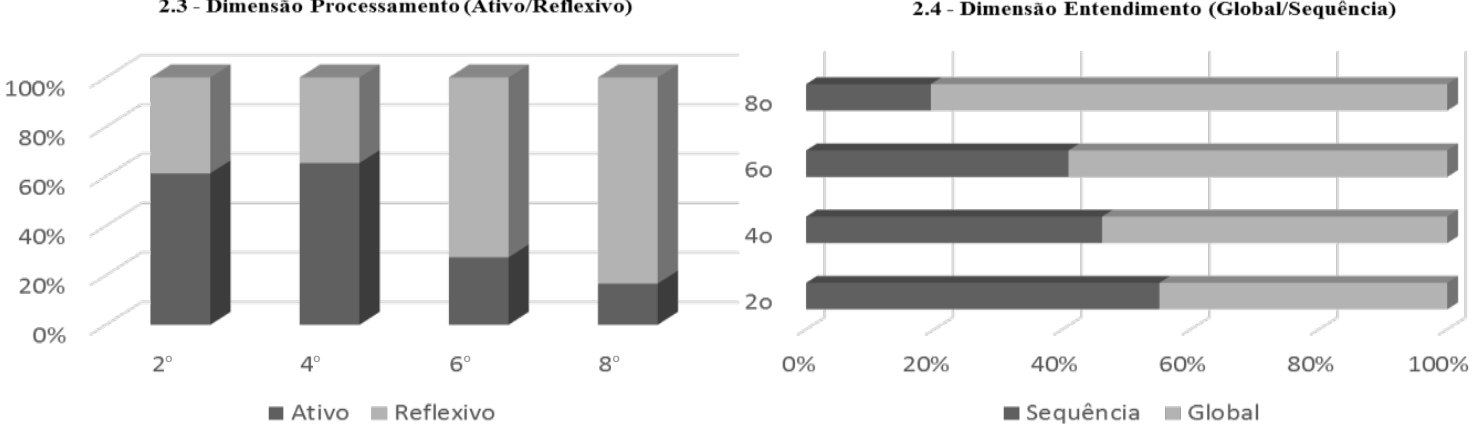

Fonte: Dados da pesquisa.

Nota: Teste do Qui-quadrado por dimensão (p-valor e decisão). Percepção (0,3705 $\rightarrow$ Não se pode rejeitar Ho). Entrada (0,0001 $\rightarrow$ Rejeita Ho). Processamento (0,0002 $\rightarrow$ Rejeita Ho). Entendimento (0,0173 $\rightarrow$ Rejeita Ho).

Esse resultado foi confirmado pelo teste de independência $\left(x^{2}\right)$, que demonstrou que não existe associação entre o estilo de aprendizagem na dimensão Percepção e o período do curso em que o aluno se encontra. Por outro lado, nas demais dimensões, quando analisado os períodos, observaram-se associação entre o período em que o estudante se encontra e os estilos de aprendizagem (rejeitou-se a hipótese nula no teste de independência $x^{2}$ ).

No que se refere à dimensão Entrada (a forma como o indivíduo receberá o dado), os resultados sugerem haver uma migração de um perfil visual para um verbal. Além disso, os estudantes no início de curso possuem um estilo Ativo na dimensão Processamento, migrando posteriormente, para um estilo Reflexivo.

Na dimensão Entendimento, a predominância do estilo Sequência no início do curso, com uma migração para o estilo Global nos períodos finais, sugere uma maior capacidade de desenvolver o raciocínio do todo para parte. Em contrapartida, da parte para o todo, como no início do curso. A despeito do presente estudo não ser longitudinal, do tipo coorte, os resultados sugerem uma evolução do estudante ao longo do curso, o que se pode deduzir que: (1) existe uma influência do curso na forma de o estudante aprender, (2) os métodos e as técnicas utilizados pelos professores não podem ser padronizados ao longo do curso, (3) a compreensão dos perfis dos estudantes ao longo dos períodos pode potencializar a melhoria da eficiência do processo de ensino-aprendizagem.

Analisando os estilos de aprendizagem e sua relação com a idade dos participantes, conforme Gráfico 3, verificou-se que, apenas na dimensão Percepção, a relação entre idade e estilo de aprendizagem é independente, ou seja, não existe associação entre a idade e o estilo de aprendizagem do estudante.

Por outro lado, nas demais dimensões, (i) Entrada, (ii) Processamento e (iii) Entendimento, verificou-se que existe uma associação significativa. Na dimensão Entrada, verificou-se que os estudantes com idade igual ou inferior a 20 anos e superior a 30 anos apresentaram uma predominância pelo estilo visual, enquanto na faixa etária acima de 20 anos e menor que 30, a predominância foi do estilo verbal. 


\section{Gráfico 3 - Distribuição de Frequência dos Estilos de Aprendizagem por Dimensão/Idade}
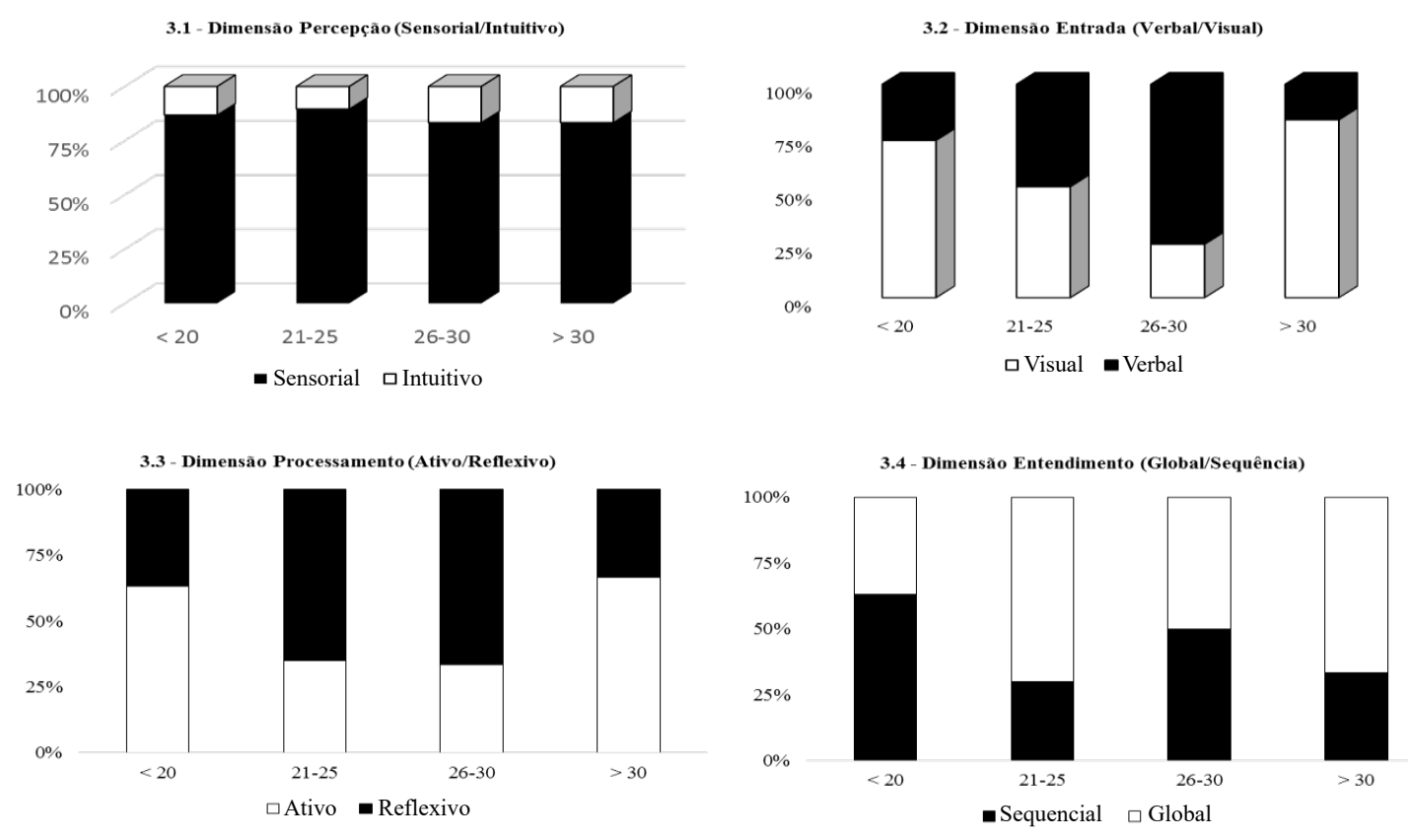

Fonte: Dados da pesquisa.

Nota: Teste do Qui-quadrado por dimensão (p-valor e decisão). Percepção (0,8948 $\rightarrow$ Não se pode rejeitar Ho). Entrada $(0,0008 \rightarrow$ Rejeita Ho). Processamento $(0,0191 \rightarrow$ Rejeita Ho). Entendimento $(0,0068 \rightarrow$ Rejeita Ho).

A compreensão sobre a existência de uma mudança no estilo de aprendizagem, em decorrência da idade, exige a realização de um estudo longitudinal do tipo coorte, pois a coleta de dados ocorreria à medida que se avança a idade, possibilitando confirmar se ocorre, de fato, uma mudança no estilo a cada período transcorrido pelo estudante. Considerando que o processo de ensino-aprendizagem, independente do formalismo, ocorre diariamente, é possível que, em decorrência das experiências vividas, processadas e assimiladas, os indivíduos mudem a forma como aprendem. Aliás, na perspectiva de teorias didáticas contemporâneas, é o que se espera (LIBÂNEO, 2005). Considerando, ainda, que a abordagem sociocultural tem forte influência na cultura didática do brasileiro, maior é a chance de que, à medida que os anos passem, os estudantes alterem a forma como aprendem (MUZIKAMI, 1986).

Na dimensão Processamento, observaram-se, mais uma vez, similaridades na distribuição entre faixas etárias maiores e menores, pois cerca de $70 \%$ dos estudantes com idades iguais ou inferiores a 20 anos e aqueles com idade superior a 30 anos apresentaram o estilo Ativo. Entre os estudantes da faixa etária acima de 20 anos e menor que 30, a predominância foi pelo estilo Reflexivo (em torno de $62,5 \%$ ). Considerando que a maioria dos alunos é da faixa etária intermediária ( $>20$ e $<30$ ), isso justifica a predominância do estilo Reflexivo nessa amostra.

Esses resultados reforçam a necessidade de integrar estratégias didáticas que estimulam o raciocínio e a capacidade de reflexão, com processos ativos na participação e interação do aluno com o objeto de aprendizagem e o meio no qual está inserido. Como não se trata de um processo uniforme e linear, dado que características individuais sempre interferirão no padrão médio observado, compete ao professor gerir as estratégias didáticas que potencializem a aprendizagem da maioria, trabalhando as exceções de modo particular (LUZ; GAMA; SANTOS, 2004; LIBÂNEO, 2005).

Por fim, na dimensão Entendimento, a predominância pelo estilo Global se destacou e o Teste de Independência do Qui-quadrado evidenciou haver relação entre a idade e o estilo. Curiosamente, os alunos das faixas etárias entre 21 a 25 anos e acima de 30, apresentaram uma preferência pelo estilo Global, aquele no qual o método dedutivo seria mais adequado ao processo de ensino-aprendizagem. Entre os estudantes mais jovens, a predominância pelo estilo Sequencial $(62,5 \%)$ pode ser explicada pela experiência didática pregressa, em que o processo de ensino é fragmentado e ocorre a partir da indução. $\mathrm{Na}$ faixa etária entre 26 e 30 anos, a distribuição foi de $50 \%$ para o sequencial e $50 \%$ para o global, sugerindo não haver distinção entre esse grupo. A questão da idade e os estilos de aprendizagem se justificam em função do processo de desenvolvimento cognitivo e está relacionado a fatores bioquímicos, pois o tempo os altera permanentemente (WALLON, 1995). Logo, compreender essa relação é importante para se definir as estratégias e abordagens didáticas com maiores chances de sucesso.

Posteriormente, analisaram-se os estilos de aprendizagem por gênero, conforme o Gráfico 4. A questão de gênero tem sido estudada na área de contabilidade sob diversos aspectos, em geral, buscando verificar a associação entre gênero e outras variáveis de interesse (NOGUEIRA et al., 2013; LIMA FILHO; BEZERRA; JESUS SILVA, 2016).

No que se refere à associação entre gênero e o estilo de aprendizagem, o presente estudo corroborou os achados anteriores, tais como em Nogueira, Costa, Takamatsu e Reis (2013) e Lima Filho, Bezerra e Jesus Silva (2016), pois não se pôde rejeitar a hipótese nula () para três das quatro dimensões, ou seja, não existe associação entre gênero e o estilo 
de aprendizagem. No que se refere à dimensão Entrada, verificou-se associação significativa com o gênero, pois se refere ao modo de preferência do estudante quanto à recepção do conteúdo.

\section{Gráfico 4 - Distribuição de Frequência dos Estilos de Aprendizagem por Dimensão/Gênero}

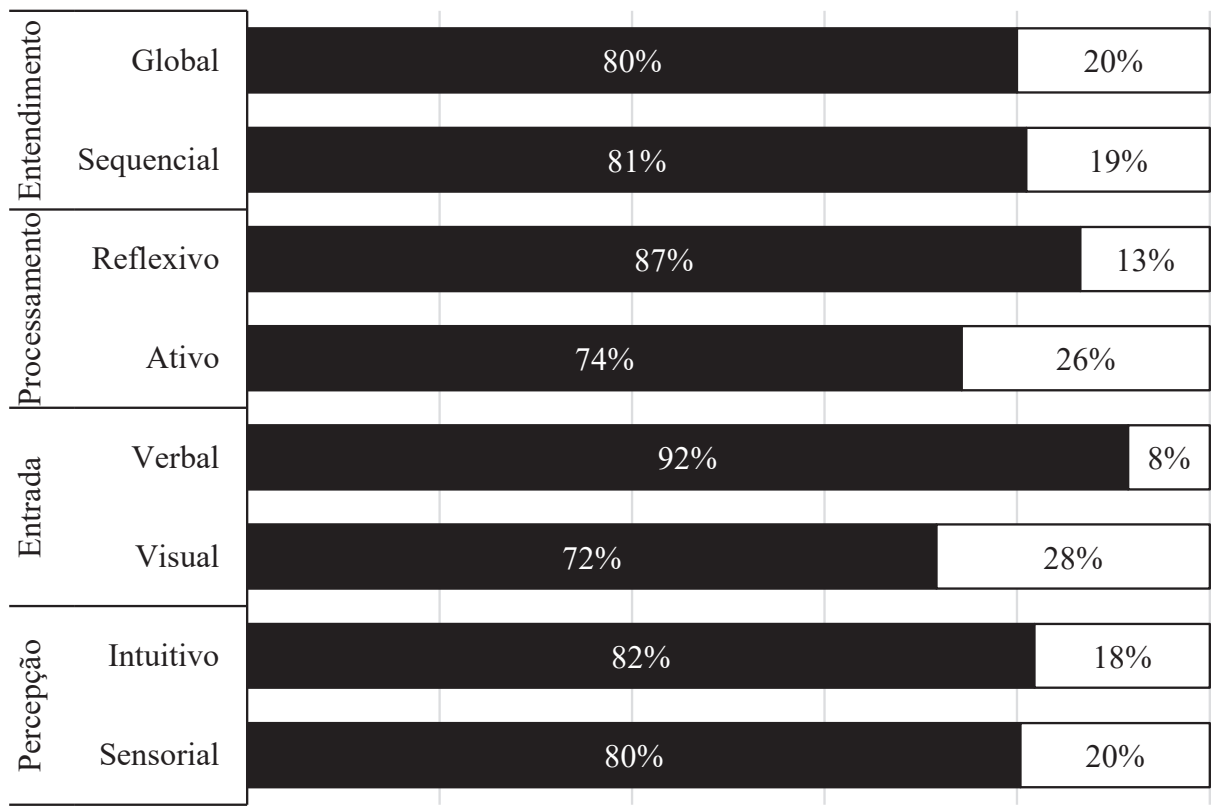

- Feminino

口Masculino

Fonte: Dados da pesquisa

A partir dos resultados obtidos, infere-se, para essa amostra, que os homens têm preferência menos intensa pelo estilo Verbal. A compreensão sobre os motivos que fundamentam tal diferença pode se associar às experiências de estímulos vivenciadas pelos estudantes. Segundo Wallon (1995), os estímulos que os indivíduos recebem ao longo da vida, sobretudo, até a pré-adolescência, influenciam sobremaneira na forma como ele lidará com o processo de ensino e aprendizagem. Considerando que, historicamente, os estímulos recebidos pelos meninos e meninas são claramente diferentes (DUARTE DA SILVA et al., 1999), esse resultado se justifica.

Por fim, em última instância, analisaram-se a associação entre o estilo de aprendizagem e o estado civil dos estudantes, como indicado no Gráfico 5. Trata-se de uma questão eminentemente delicada às mulheres, que, ainda em um mundo que questiona os padrões tradicionais de relações familiares e profissionais, desempenham duplas ou triplas jornadas, mesmo assumindo responsabilidades similares às dos homens (CAMARGO et al., 2013).

\section{Gráfico 5 - Distribuição de Frequência dos Estilos de Aprendizagem por Dimensão/Estado Civil}

5.1 - Dimensão Percepção (Sensorial/Intuitivo)
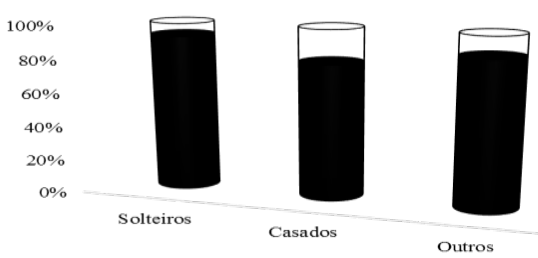

- Sensorial aIntuitivo

5.3 - Dimensão Processamento (Ativo/Reflexivo)
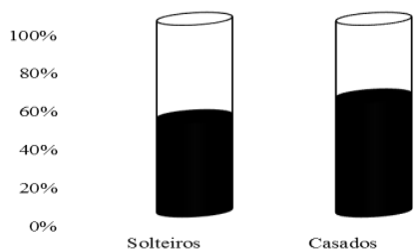

Casados

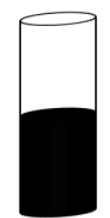

Outros 5.2 - Dimensão Entrada (Verbal/Visual)
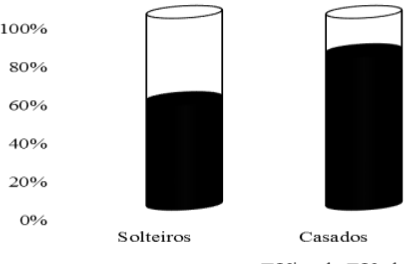

Casados

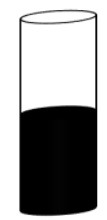

-Visual averbal

Outros

5.4 - Dimensão Entendimento (Global/Sequência)
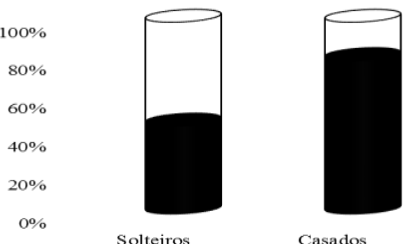

Casados

- Sequencial aGiobal

Fonte: Dados da pesquisa 
Nota: Teste do Qui-quadrado por dimensão (p-valor e decisão). Percepção (0,5517 $\rightarrow$ Não se pode rejeitar Ho). Entrada $(0,5155 \rightarrow$ Não se pode rejeitar Ho). Processamento (0,8932 $\rightarrow$ Não se pode rejeitar Ho). Entendimento (0,3212 $\rightarrow$ Não se pode rejeitar Ho).

Especificamente na amostra estudada, verificou-se que a distribuição de frequência dos estudantes solteiros, casados e outros foi relativamente homogênea nas quatro dimensões. Entretanto, nas dimensões Entrada e Entendimento, os participantes casados apresentaram uma maior proporção nos estilos Visual e Sequencial, respectivamente. Porém, essa maior frequência não foi significativa a ponto de se observar associação entre o estado civil e o estilo de aprendizagem. Logo, os testes de independência (Qui-quadrado) aplicados nas quatro dimensões apresentaram não rejeição da hipótese nula, podendo-se inferir que não existe associação entre o estilo de aprendizagem e gênero. De todo modo, devem ser consideradas as limitações da amostra estudada, sobretudo, pelo fato de os participantes casados serem a minoria, porém, eles apresentaram uma distribuição ligeiramente superior, como comentado sobre as dimensões Entrada e Entendimento.

\section{CONSIDERAÇÕES FINAIS}

O objetivo do presente estudo foi identificar os estilos de aprendizagem dos estudantes de Ciências Contábeis de uma universidade privada do estado de Minas Gerais. O estudo de natureza descritiva, do tipo survey e com abordagem quantitativa, utilizou o ILS de Silverman e Soloman (1991), desenvolvido a partir do modelo de Felder e Silverman (1988) e traduzido por Kuri (2004), em uma amostra de 133 estudantes de Ciências Contábeis dos $2^{\circ}, 4^{\circ}, 6^{\circ}$ e $8^{\circ}$ períodos, de modo a verificar se existia associação entre os estilos de aprendizagem e o estágio do curso em que o aluno se encontrava. Os dados foram coletados no segundo semestre de 2016 e analisados a partir da estatística descritiva e do Teste de Independência do Qui-quadrado $\left(x^{2}\right)$.

Os resultados evidenciaram que, na amostra estudada, os estudantes de Ciências Contábeis são, em sua maioria, mulheres (80\%), solteiras (90\%) e com faixa etária até 25 anos (80\%). Entre os estilos de aprendizagem, destacaram-se: Sensorial, Visual, Reflexivo e Global. Em termos de associação entre os estilos de aprendizagem e as características dos estudantes (período, gênero, idade e estado civil), verificou-se associação estatisticamente significativa apenas com o período e a idade, evidenciando que, ao longo do curso e à medida que a idade avança, os estilos de aprendizagem podem se alterar. Entretanto, as evidências precisam ser confirmadas a partir de um estudo longitudinal do tipo coorte.

Os resultados encontrados são parcialmente convergentes com os estudos anteriores, porém, trazem novas contribuições quando indicam associação entre o estilo de aprendizagem, o período e a idade, pois evidencia uma necessidade de os professores e as instituições considerarem que a faixa etária e o período em que o estudante se encontra, afetam a forma como ele aprende (SILVA; OLIVEIRA NETO, 2010; SILVA et al., 2016; SOUZA; AVELINO; TAKAMATSU, 2017; BORGES; LEAL; PEREIRA, 2017).

Além disso, dados os perfis predominantes nesta amostra, é possível inferir que as estratégias didáticas que estimulam os sentidos dos estudantes através de recursos visuais, os fazendo refletir sobre o conteúdo em um processo dedutivo (do todo para a parte), tendem a ter maiores chances de sucesso nos processos de ensino e aprendizagem. Desse modo, os resultados do estudo contribuem com as instituições e docentes, com o intuito de reforçar a importância de um diagnóstico prévio dos discentes, de modo que as estratégias didáticas utilizadas sejam direcionadas à maior probabilidade de um processo de ensino-aprendizagem eficaz.

Apesar das contribuições, o estudo apresenta limitações relacionadas à amostra por acessibilidade, técnica de análise de dados que não avalia causalidade (ainda que probabilística) e a não consideração de outras variáveis, como a nota, o tempo médio de dedicação, a atividade profissional desenvolvida, entre outras. Como sugestão para pesquisas futuras, diversas questões podem ser respondidas, tais como: (i) realizar um estudo do tipo coorte para analisar se, ao longo do curso, os estudantes mudam de fato seus estilos de aprendizagem; (ii) identificar os mecanismos que justificam as diferenças entre homens e mulheres; (iii) analisar a existência de uma combinação ótima de professor-aluno, em termos de estilo de aprendizagem; (iv) identificar como lidar com as diferenças de estilo de aprendizagem no atual contexto educacional; (v) verificar de que modo a aptidão ou a utilização da tecnologia afetam no estilo de aprendizagem.

\section{REFERÊNCIAS}

ANTONELLI, R. C.; COLAUTO, R. D.; CUNHA, J. V. A. Expectativa e satisfação dos alunos de Ciências Contábeis com relação às competências docentes. REICE. Revista Iberoamericana sobre Calidad, Eficacia y Cambio en Educación. Madrid, v. 10, n. 1, p. 74-91, 2012. Disponível em: <https://revistas.uam.es/index.php/reice/article/view/3075/3287. >. Acesso em: 30 Jan. 2017.

APOSTOLOU, B. et al. Accounting education literature review. Journal of Accounting Education, v. 33, n. 2, p. 69-127, 2015.

BALDWIN, B. A.; RECKERS, P. M. J. Exploring The Role of Learning Style Research in Accounting Education Policy. Journal of Accounting Education, v. 2, n. 2, Autumn, p. 63-76, 1984.

BORGES, L. F. M.; LEAL, E. A.; PEREIRA, J. P. Relação entre rendimento acadêmico e os estilos de aprendizagem: um estudo na discipina de análise de custos. In: Semead - Seminários em Administração, 10., 2017, São Paulo. Anais... São Paulo: [s.n.]. 2017. p. 1-16.

CAMARGO, E. M. C. et al. Estresse percebido, comportamentos relacionados à saúde e condições de trabalho de professores universitários. Psicologia Argumento. Curitiba: v. 31, n. 75, p. 589-597, out./dez. 2013. 
CAMERON, R. et al. The Importance of Understanding Student Learning Styles in Accounting Degree Programs. Australian Accounting Review, n. 3, p. 218-231, 2015.

CHEN, C. C.; JONES, K. T.; MORELAND, K. Differencies in Learning Styles: Implications for Accounting Education and Practice. The CPA Journal, v. 84, n. 8, p. 46-51, ago. 2014. Disponivel em: <http://link.galegroup.com/apps/doc/A379569596/AONE?u=capesesid=AONEexid=e96d3dd7. > . Acesso em: 03 Abr. 2017.

CONCEIÇÃO, M. G. et al. Estilos de Aprendizagem sob a ótica do Inventário de David Kolb: um Estudo de Caso com os Alunos de Graduação do Curso de Ciências Contábeis da UFBA. Revista de Contabilidade da Bahia. Salvador, v. 1, n. 1, p. 1-12, jan./jun. 2013. Disponível em: <http://web.crcba.org.br:8080/seer/index.php/volume012013/

article/view/8. >. Acesso em: 10 Jan. 2017

COOPER, D. R.; SCHINDLER, P. S. Métodos de pesquisa em Administração. Tradução de Luciana de Oliveira Rocha. 7 ed. Porto Alegre: Bookman, 2003.

CRUZ, A. P. C. et al. Quais atributos definem o bom professor? Percepção dos alunos de Ciências Contábeis ofertados no Brasil e Portugal. Revista Ambiente Contábil. Natal, v. 9, n. 1, p. 163-184, jan./jun. 2017. Disponível em: <https://periodicos.ufrn.br/ambiente/article/view/7222/7868. >. Acesso em: 30 Jan. 2017.

DIAS, G. P. P.; SAUAIA, A. C. A.; YOSHIZAKI, H. T. Y. Estilos de aprendizagem Felder-Silverman e o aprendizado com jogos de empresa. RAE-Revista de Administração de Empresas. São Paulo, v. 53, n. 5, p. 469-484, set./out. 2013.

DUARTE DA SILVA, C. A. et al. Meninas bem-comportadas, boas alunas; meninos inteligentes, indisciplinados. Cadernos de Pesquisa. São Paulo, v. 107, p. 207-225, 1999.

DUFF, A. The role of cognitive learning styles in accounting education: developing learning competencies. Journal of Accounting Education, v. 22, p. 29-52, 2004.

FATT, J. P. T. Learnings Styles in Accounting Education. Asian Review of Accounting, v. 3, n. 1, 1995

FÁVERO, L. P. et al. Análise de dados: modelagem multivariada para tomada de decisão. 1 ed. Rio de Janeiro: Campus Elsevier, 2009.

FELDER, R. M.; SILVERMAN, L. K. Learning and Teaching Styles In Engineering Education. Engr. Education, v. 78, n. 7, p. 675-681, 1988. Disponível em: <http://www4.ncsu.edu/unity/lockers/users/f/felder/public/Papers/LS-1988.pdf>. Acesso em: 28 Jan. 2017.

FELDER, R.; SOLOMAN, B. Index of Learning Styles Questionnaire, 1991 North Carolina State University. Disponível em: < https://www.webtoolsncsu.edu/Learningstyles. Acesso em: 28 Jan. 2017.

GUERRA, C. J. O.; TEIXEIRA, A. J. C. Os Impactos da Adoção de Metodologias Ativas no Desempenho dos Discentes do Curso de Ciências Contábeis de Instituição de Ensino Superior Mineira. Revista de Educação e Pesquisa em Contabilidade. Brasília, v. 10, n. 4, p. 380-397, out./dez. 2016.

HOLTZBLATT, M.; TSCHAKERT, N. Expanding your accounting classroom with digital video technology. Journal of Accounting Education, v. 29, p. 100-121, jun.-set. 2011.

KURI, N. P. Tipos de personalidade e estilos de aprendizagem: proposições para o ensino de engenharia. São Carlos: Universidade de São Carlos, 2004

LIBÂNEO, J. C. As Teorias Pedagógicas Modernas Revisitadas pelo Debate Contemporâneo na Educação. In: LIBÂNEO, J. C.; SANTOS, A. Educação na era do conhecimento em rede e transdiciplinaridade. 1 ed. Campinas: Alínea. cap. 1, p. 15-58, 2005. Disponível em: <https://xa.yimg.com/kq/groups/13436574/790228301/name/correntes+pedag\%2B\%C2\%A6gicas+lib\%2B\%C3\%B3neo.pdf>. Acesso em: 5 Fev. 2017.

LIMA FILHO, R. N.; BEZERRA, E. S.; JESUS SILVA, T. B. Estilo de aprendizagem dos alunos do curso de Ciências Contábeis. Revista GUAL. Florianópolis, v. 9, n. 2, p. 95-112, maio 2016

LINDEMANN, V. Estilos de aprendizagem: buscando a sinergia. Porto Alegre: . Universidade Federal do Rio Grande do Sul, 2008. p. 162

LUZ, A. A. B. S.; GAMA, A. F.; SANTOS, A. R. B. A Neurobiologia, a inteligência espacial e a psicolíngúistica: uma abordagem alternativa no processo de ensino-aprendizagem. In: Reunião Anual da ANPEd, 27., 2004, Caxambu. Anais... Caxambu: [s.n.], 2004. p. 1-13.

MARQUES, V. A.; SILVA, C. E. S.; SALVIANO, R. A. G. O que importa na escolha pelo curso de Ciências Contábeis? Revista de Contabilidade da UFBA, Salvador, v. 10, n. 3, p. 176-197, set./dez. 2016. Disponível em: <https://portalseer.ufba.br/index.php/ rcontabilidade/article/view/17767/13067. >. Acesso em: 30 Jan. 2017

MAROUES, V. A. et al. Debatendo o fazer didático: a percepção de estudantes de Ciências Contábeis acerca das estratégias didáticas utilizadas. Revista de Administração e Contabilidade - RAC (IESA), Santo Ângelo, v. 16, n. 31, p. 1-19, jan./jul. 2017.

MIRANDA, L.; MORAIS, C. Estilos de aprendizagem: o questionário CHAEA. Adaptado para língua portuguesa. Revista de Estilos de Aprendizagem, v. 1, n. 1, p. 66-87, abr. 2008. Disponível em: <https://www.sswm.info/sites/default/files/reference_attachments/ MIRANDA\%20MORAIS\%202008\%20Estilos\%20de\%20Apredizagem\%20\%20PORTUGUESE.pdf>. Acesso em: 03 Abr. 2017.

MUZIKAMI, M. G. N. Ensino: As abordagens do processo. São Paulo: EPU, 1986.

NOGUEIRA, D. R. et al. Fatores que impactam no desempenho acadêmico: uma análise dos discentes do curso de Ciências Contábeis no ensino presencial. RIC - Revista de Informação Contábil, Recife, v. 7, n. 3, p 51-62, jul./set. 2013. Disponível em: <http:// periodicos.ufpe.br/revistas/ricontabeis/article/view/7991/8063.>. Acesso em: 20 Jan. 2017.

OLIVEIRA, A. J. et al. Estilos de Aprendizagem e Estratégicas Ludopedagógicas: Percepções no Ensino da Contabilidade. Advances in Scientific and Applied Accounting, São Paulo, v. 6, n. 2, p. 236-262, 2003 
OSPINA, M. A. P.; SALAZAR, L. I. D.; MENESES, J. S. C. M. Modelos de estilos de aprendizaje: una actualización para su revisión y análisis. Revista Colombiana de Educacion, Bogotá, v. 64, p. 79-105, Primer Semestre 2013.

PAVIONE, C. S. N.; AVELINO, B. C.; FRANCISCO, J. R. S. Fatores que Influenciam o Processo de Ensino-Aprendizagem sob a Perspectiva de Estudantes do Curso de Ciências Contábeis: Análise em uma Instituição de Ensino Superior de Minas Gerais. Revista de Educação e Pesquisa em Contabilidade, Brasília, v. 10, n. 2, p. 196-219, abr./jun. 2016.

RAMSAY, A.; HANLON, D.; SMITH, D. The association between cognitive style and accounting students' preference for cooperative learning: an empirical investigation. Journal of Accounting Education, v. 18, n. 3, p. 215-228, 2000.

RAUPP, F. M.; BEUREN, I. M. Metodologia Aplicável às Ciências Sociais. In: BEUREN, I. M. Como elaborar trabalhos monográficos em Contabilidade: teoria e prática. São Paulo: Atlas, 2006. p. 76-97,.

REZENDE, M. G.; LEAL, E. A. Competências Requeridas dos Docentes do Curso de Ciências Contábeis na Percepção dos Estudantes. Sociedade, Contabilidade e Gestão. Rio de Janeiro, v. 8, n. 2, p. 145-160, maio/ago. 2013. Disponível em: <http://atena.org.br/revista/ojs-2.2.3-08/index.php/ufrj/article/viewFile/1878/1736.>. Acesso em: 30 Jan. 2017.

SANTOS, C. A. et al. Estilos de Aprendizagem: um estudo empírico com alunos de Ciências Contábeis na Universidade Federal do Mato Grosso do Sul. Revista Razão Contábil e Finanças, Fortaleza v. 4, n. 2, p. 156-178, jul./dez. 2013. Disponível em: <http:// institutoateneu.com.br/ojs/index.php/RRCF/article/view/90/78. >. Acesso em: 11 Jan. 2017.

SANTOS, D. F. et al. Estilos de Aprendizagem: Estudo com Estudantes de Ciências Contábeis em uma Universidade Pública. Revista de Contabilidade da UFBA, Salvador: v. 8, n. 1, p. 37-53, jan./abr. 2014. Disponivel em: <https://www.portalseer.ufba.br/index.php/rcontabilidade/article/view/8583.>. Acesso em: 15 Jan. 2017.

SANTOS, M. A. et al. A construção do conhecimento sobre ensino e aprendizagem em contabilidade: um olhar sobre os congressos USP e ANPCONT no período de 2007 a 2011. Revista Evidenciação Contábil e Finanças, João Pessoa: v. 1, n. 1, p. 71-84, jan./ jun. 2013.

SCHMIDT, C. S.; DOMINGES, M. J. S. Estilos de aprendizagem: um estudo comparativo. Revista da Avaliação da Educação Superior, Campinas: v. 21, n. 2, p. 361-385, jul. 2016. Acesso em: 05 Jan. 2016.

SILVA, M. G.; RUFINO, M. C. Comportamento Docente no Ensino de Graduação em Enfermagem: a percepção dos alunos. Revista Latino-Americana de Enfermagem, Ribeirão Preto: v. 7, n. 4, p. 45-55, out. 1999.

SILVA, D. M.; OLIVEIRA NETO, J. D. O Impacto dos Estilos de Aprendizagem no Ensino de Contabilidade. Revista Contabilidade Vista e Revista. Belo Horizonte: 21, n. 4, p. 123-156, out./dez. 2010. Disponível em: <http://revistas.face.ufmg.br/index.php/contabilid devistaerevista/article/view/810/pdf54.>. Acesso em: 2 Fev. 2017.

SILVA, D. M. et al. Estilos de aprendizagem e desempenho acadêmico na Educação a Distância: uma investigação em cursos de especialização. Revista Brasileira de Gestão e Negócios, São Paulo: v. 17, n. 57, p. 1300-1316, jul./set. 2016.

SOUZA, L. M.; AVELINO, B. C.; TAKAMATSU, R. T. Estilos de aprendizagem e influência no processo de ensino-aprendizagem: análise empírica na visão de estudantes de Contabilidade. Revista Ambiente Contábil, Natal: v. 9, n. 2, p. 379-400, jul./dez. 2017. Disponível em: <https://periodicos.ufrn.br/ambiente/article/view/10850/8611>. Acesso em: 05 Jan. 2018.

TURRA, S.; JACOMOSSI, F. A.; BIAVATT, V. T. Análise da preferência do estilo de aprendizagem dos alunos de graduação em Ciências Contábeis. Revista de Contabilidade da UFBA, Salvador: v. 9, n. 3, p. 118-134, set./dez. 2015. Disponível em: <https://portalseer.ufba.br/index.php/rcontabilidade/article/view/13274/10126.>. Acesso em: 15 Dez. 2015.

VIEIRA JÚNIOR, N.; COLVARA, L. D. A importância do professor conforme estilos de aprendizagem e modelos mentais. In: Congresso Brasileiro de Ensino de Engenharia, 14., Passo Fundo: ABENGE - Associação Brasileira de Ensino de Engenharia, 2006, p. 1239-1250.

WALLON, H. As origens do caráter na criança. Tradução de Heloysa Dantas de Souza Pinto. São Paulo: Nova Alexandria, 1995. 